\title{
Comportamiento de vacas lecheras primíparas y sus cruzas en un sistema a pastoreo de Entre Ríos (Argentina)
}

\author{
Mancuso, W.A. ${ }^{1}$; Marini, P.R. ${ }^{2}$ \\ ${ }^{1}$ Instituto Nacional de Tecnología Agropecuaria (INTA) EEA Paraná, Ruta Provincial 11, km 12,5 - Oro Verde \\ (3101), Entre Ríos (Argentina), E-mail: wmancuso@parana.inta.gov.ar. ${ }^{2} \mathrm{Facultad}$ de Ciencias Veterinarias, \\ Univ. Nac. Rosario, Ovidio Lagos y Ruta 33, Casilda (2170), Santa Fe (Argentina). \\ E-mail: pmarini@fveter.unr.edu.ar.
}

\begin{abstract}
Resumen
Mancuso, W.A.; Marini, P.R.: Comportamiento de vacas lecheras primíparas y sus cruzas en un sistema a pastoreo de Entre Ríos (Argentina). Rev. vet. 23: 2, 138-143, 2012. Se planteó como objetivo evaluar distintos genotipos lecheros durante su primera lactancia, en un sistema a pastoreo con suplementación de la cuenca lechera de Entre Ríos, Argentina. Se analizaron datos retrospectivos de lactancias de vacas primíparas pertenecientes a cinco genotipos lecheros: Holstein (H), H x Jersey (F1), F1 x Pardo Suizo (P), F1 x Guernsey (G) y retrocruza de las vacas triple cruza con $\mathrm{H}(\mathrm{R})$. Las vacas presentaron diferentes pesos al parto en los años 2007 y 2010, en tanto la edad al primer parto mostró diferencias en la F1 en 3 de los 4 años. El $\mathrm{G}$ aparece como uno de los genotipos con menor y más constante intervalo parto-concepción (ipc) en todos los años, en tanto F1 mostró los menores valores para ese parámetro en los últimos tres períodos y $\mathrm{H}$ siempre mostró los mayores, confirmando que mayores producciones se asocian a peores indicadores reproductivos. El número de servicios por preñez y los días en lactancia acompañaron en general la tendencia del ipc, pero revelaron una alta variabilidad dentro de cada genotipo, rotando la performance de los genotipos según el año. La producción de leche estuvo por encima de 6.000 litros en todos ellos, destacándose $\mathrm{H}$ cuando las condiciones ambientales y de alimentación se lo permitieron. La producción de grasa butirosa y proteína total se presentó muy variable entre genotipos y años, siendo $\mathrm{H}$ y $\mathrm{G}$ los de mayor producción en todos los años. Puede concluirse que las variaciones dentro de cada genotipo analizado y las diferentes respuestas que cada uno de ellos produjo, no permiten explicar adecuadamente la posible adaptación o no de los animales al ambiente y manejo del sistema durante el período considerado, aunque podría afirmarse que los genotipos F1 y $\mathrm{G}$ son los más estables en producción y con mejores respuestas reproductivas para estas condiciones.
\end{abstract}

Palabras clave: vaca lechera, genotipos, sistema a pastoreo, primer lactancia, reproducción, producción de leche.

\begin{abstract}
Mancuso, W.A.; Marini, P.R.: Behavior of primiparous dairy cows and their crossbred in a shepherding system from Entre Rios (Argentina). Rev. vet. 23: 2, 138-143, 2012. The purpose of this work was to evaluate different dairy genotypes during their first lactation in a grazing system with supplementation in Entre Rios, Argentina. We analyzed retrospective data from lactations of primiparous cows from five dairy genotypes: Holstein $(\mathrm{H}), \mathrm{H} \mathrm{x}$ Jersey (F1), F1 x Brown Swiss (P), F1 x Guernsey (G) and triple backcross of cows crossed with $\mathrm{H}$. The cows showed different birth weights in 2007 and 2010, while age at first birth showed differences in F1 in 3 of the 4 years. The genotype G appears to have the lowest and most constant calving to conception interval (ipc) in each year, F1 was the best in the last three periods and $\mathrm{H}$ always showed a low reproductive efficiency, confirming that the major productions were associated with poorer reproductive indicators. The number of services per pregnancy and lactation on the whole go with the general ipc trend, but has a great variability within each genotype, rotating the performance of the genotypes according to the year. Milk production was above 6,000 liters in all of them, being $\mathrm{H}$ the one that stood out when environmental and food conditions were favorable. Production of butiric fat and total protein were highly variable among genotypes and years, being $\mathrm{H}$ and $\mathrm{G}$ the most productive. It can be concluded that the variations within each genotype analyzed and the different
\end{abstract}


responses that each of them produced do not explain adequately the possible adaptation of the animals to the current environment and management, although it could be argued that F1 and $\mathrm{G}$ genotypes are the most stable as regards production and offer the best reproductive responses for these conditions.

Key words: dairy cow, genotypes, grazing systems, first lactation, reproduction, milk production.

\section{INTRODUCCIÓN}

Las regiones en vías de desarrollo utilizan los distintos sistemas de cruzamiento de razas bovinas como medio para obtener un aumento de la producción de leche y sólidos ya que, por poseer situaciones menos favorables para razas puras, éstas no pueden demostrar todo su potencial ${ }^{3,7}$.

Este aspecto es aún más importante cuando se consideran áreas con algunas limitantes de clima y/o suelo, en las cuales se desarrollan cada vez más las producciones lecheras ${ }^{9}$. Un ejemplo es la cuenca lechera entrerriana, donde muchos productores han incrementado su interés en los últimos años sobre las cruzas, en pos de encontrar un genotipo más adaptado a sus sistemas a pastoreo con suplementación, debido a las limitaciones agroecológicas que poseen para aquellos animales de alto mérito genético.

Entre las razones que generaron ese interés se cuentan la menor fertilidad actual de las vacas Holstein, sus problemas crecientes en cuanto a facilidad de parto, las superficies de campo limitadas para producir el volumen de forraje necesario para abastecer a animales de alto potencial, las dificultades económicas para mantener esquemas de producción con medianos a altos niveles de suplementación concentrada y, dentro de lo vinculado a aspectos comerciales, los cambios que se están dando en la negociación del precio de la leche, basado cada vez más en sólidos útiles ${ }^{5,10}$.

Frente a la complejidad de la temática y a la falta de información más ajustada acerca del comportamiento local de otras razas lecheras y sus cruzas, se plantea el objetivo de evaluar el comportamiento de distintos genotipos lecheros y sus cruzas en su primera lactancia, en un sistema a pastoreo con suplementación estratégica, típico de la cuenca lechera de Entre Ríos, Argentina.

\section{MATERIAL Y MÉTODOS}

Se evaluaron rodeos pertenecientes a un establecimiento lechero comercial ubicado en el centro-oeste de la Provincia de Entre Ríos ( $32^{\circ} 00^{\prime}$ Sur y $59^{\circ} 34^{\prime}$ Oeste), donde todas las vacas de primera parición de los diferentes genotipos se manejaron en la misma instalación de ordeño, pastoreando las mismas pasturas y verdeos y se alimentaron con la misma asignación de forrajes conservados y concentrados. En dicho sistema, se analizaron los datos retrospectivos de lactancias de vacas primíparas pertenecientes a cinco genotipos lecheros: Holstein Americano-Canadiense: "H"; H x Jersey Ca- nadiense: "F1"; F1 x Pardo Suizo: "P"; F1 x Guernsey: "G" y "Retrocruza" (P o G) x H: "R", considerando las cantidades de animales que se muestran en Tabla 1.

Las variables productivas y reproductivas evaluadas fueron: peso al primer parto $(\mathrm{kg})$, edad al primer parto (epp) en meses, intervalo parto-concepción (ipc) en días, número de servicios utilizados para la concepción (ns), días en lactancia (dl), producción de leche de la lactancia terminada ( $\mathrm{pl}$ ) en litros, grasa butirosa (GB) y proteína total (PT), ambas en $\mathrm{kg}$.

Dado que el año de parto conlleva ambientes nutricionales y climáticos distintos, los diferentes genotipos se analizaron por separado según año de parto y, como en el establecimiento las pariciones son estacionadas, no se tuvo en cuenta como efecto el momento de parto.

La Figura 1 muestra, expresados en kilogramos de materia seca (MS) promedio mensual, los diferentes aportes de: forrajes pastoreados (pasturas polifíticas $\mathrm{y}$ verdeos anuales de invierno -avena y raigrás- y de verano -sorgo forrajero y soja-), conservados (silajes de planta entera de maíz y de sorgos, henos de praderas y pulpa fresca de citrus - muy escaso y ocasional-) y concentrados (granos de maíz y de sorgo, afrechillo de trigo, harina de soja y sales minerales), que se les ofrecieron a los animales durante los cuatro años de ensayos.

El ambiente climático durante el período considerado fue muy variable, tanto en precipitaciones como en la combinación de temperatura y humedad relativa ambiente. Esto repercutió en la disponibilidad de forrajes para pastoreo y en la confección de reservas en base a verdeos y pasturas permanentes, lo cual se condice con el mayor consumo de alimentos extra-tambo (pulpa de citrus y concentrados) de los años 2008 (año "seco") e inicios de 2009.

Para visualizar los resultados de los efectos se obtuvieron los promedios y error estándar para cada variable y se realizó la comparación de medias por test de TukeyKramer HSD $(p<0,05)$ de las diferentes variables pro-

Tabla 1. Cantidad de animales analizados según genotipo y año de parición.

\begin{tabular}{lccccc}
\hline genotipo & 2007 & 2008 & 2009 & 2010 & totales \\
\hline $\mathrm{H}$ & 11 & 16 & 14 & 10 & 51 \\
$\mathrm{~F} 1$ & 227 & 168 & 125 & 88 & 608 \\
$\mathrm{G}$ & 32 & 42 & 126 & 299 & 499 \\
$\mathrm{P}$ & 33 & 66 & 42 & 16 & 157 \\
$\mathrm{R}$ & 0 & 0 & 24 & 77 & 101 \\
totales & 303 & 292 & 331 & 490 & 1416 \\
\hline
\end{tabular}




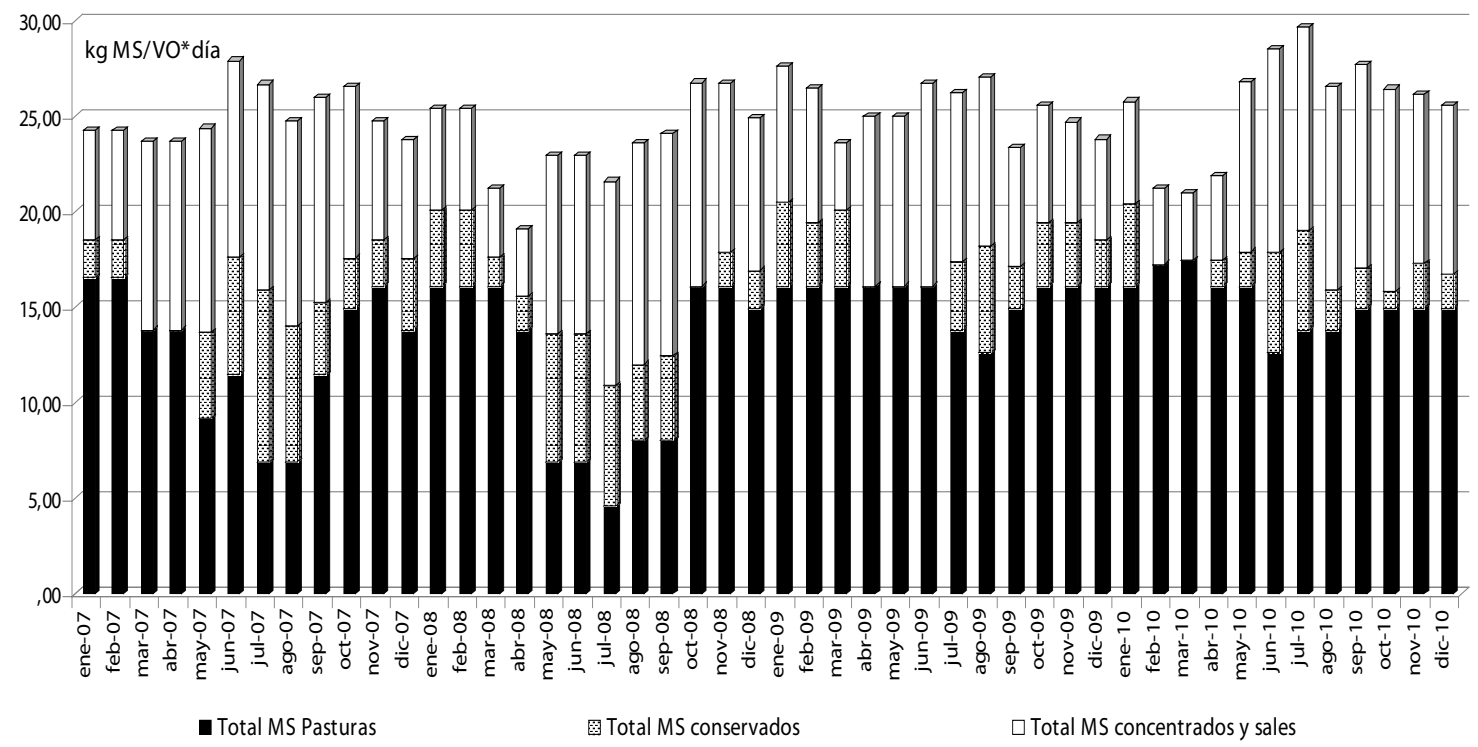

Figura 1. Oferta promedio mensual de cada grupo de alimentos ( $\mathrm{kg} / \mathrm{MS})$.

ductivas y reproductivas evaluadas. Por su parte, para la variable ns se obtuvieron la mediana y sus rangos y se la analizó a través del test Wilcoxon/Kruskal-Wallis.

\section{RESULTADOS}

Peso vivo y edad al primer parto. En la Tabla 2 se observa que las vacas de primer parto solo presentaron diferentes pesos al parto $(p<0,05)$ en los años 2007 y 2010, siendo $\mathrm{H}$ las más pesadas en 2007 y las F1 las menos pesadas en 2010. No se encontraron diferencias $(p>0,05)$ entre los demás genotipos en los otros años, aunque $\mathrm{H}$ siempre mostró una tendencia al mayor peso y F1 al menor de todos. Se observó una tendencia general al aumento de peso en todos los genotipos -salvo Holstein- a medida que avanzaron los años.

Por su parte, la edad al primer parto mostró una diferencia significativa $(\mathrm{p}<0,05)$ solamente en la F1 debido a su mayor edad en los años 2007 (29 meses), 2008 (28,4 meses) y 2010 ( 24,8 meses), mientras que los otros genotipos no superaron los 25 meses al primer parto. En los últimos 2 años se equilibraron las edades para todos los genotipos entre $23 \mathrm{y}$ 25 meses de edad, aunque con $\mathrm{F} 1$ y $\mathrm{H}$ destacándose entre los de mayor edad.

Intervalo parto-concepción, cantidad de servicios por preñez y días en lactancia. Los resultados del intervalo parto-concepción (Tabla 3) muestran que en el primer año existió un gran diferencia $(p<0,05)$ entre $P$, que estuvo casi en el óptimo para lograr un ternero por año, con los restantes genotipos, aunque esta performance se deterioró en los años siguientes. El G apareció como uno de los más constantes y bajos para este índice en todos los genotipo. $(p<0,05)$. años (entre 160 y 178 días) y la Cruza F1 fue de las mejores en los últimos tres períodos (entre 119 y 138 días).

El número de servicios por preñez, aunque acompañó en general la tendencia del ipc, sostuvo una variabilidad alta dentro de cada genotipo, lo cual no permitió detectar diferencias estadísticas (Tabla 3). Sin embargo, al analizar los días de "abierta" de la $\mathrm{H}$, se observa que hubo períodos muy grandes de no detección de celos o anestros.

Al analizar los días en lactancia se presentó nuevamente, al igual que en el ipc, una "rotación" de los genotipos con mejor y peor performance según el año, aunque el $\mathrm{H}$ apareció siempre dentro de los más altos valores en todos ellos (entre 333 y 407 días) y la F1 fue de los mejores en los últimos 2 períodos (entre 320 y 326 días) (Tabla 3).

Producción de leche. En la Figura 2 se observa que la producción de leche en lactancia terminada en general resultó muy buena para vacas de primer parto, todas por

Tabla 2. Peso vivo y edad al primer parto, según año de parición y

\begin{tabular}{|c|c|c|c|c|}
\hline & 2007 & 2008 & 2009 & 2010 \\
\hline & & peso vi & $\mathrm{o}(\mathrm{kg})$ & \\
\hline F1 & $496,36 \pm 6,65 b$ & $452,16 \pm 18,25 \mathrm{a}$ & $483,53 \pm 12,9 \mathrm{a}$ & $477,5 \pm 74,6 b$ \\
\hline G & $465,80 \pm 20,10 b$ & $455,00 \pm 19,96 \mathrm{a}$ & $531,60 \pm 11,2 \mathrm{a}$ & $530,0 \pm 66,7 \mathrm{a}$ \\
\hline $\mathrm{H}$ & $632,50 \pm 25,96 \mathrm{a}$ & SD & $530,00 \pm 29,0 \mathrm{a}$ & $534,0 \pm 84,0 \mathrm{ab}$ \\
\hline$P$ & $480,12 \pm 22,48 b$ & $461,60 \pm 19,96 a$ & $492,75 \pm 25,1 \mathrm{a}$ & $535,0 \pm 96,2 \mathrm{ab}$ \\
\hline $\mathrm{R}$ & --- & --- & $499,00 \pm 29,0 \mathrm{a}$ & $512,9 \pm 66,0 \mathrm{ab}$ \\
\hline & & edad al primer & parto (meses) & \\
\hline F1 & $29,08 \pm 0,40 \mathrm{a}$ & $28,43 \pm 0,32 \mathrm{a}$ & $25,25 \pm 0,22 \mathrm{a}$ & $24,77 \pm 0,27 \mathrm{a}$ \\
\hline G & $24,50 \pm 0,42 b$ & $25,95 \pm 0,64 b$ & $24,46 \pm 0,22 \mathrm{a}$ & $23,49 \pm 0,14 b$ \\
\hline $\mathrm{H}$ & $25,27 \pm 1,98 \mathrm{ab}$ & $26,96 \pm 1,04 \mathrm{ab}$ & $24,25 \pm 0,68 \mathrm{a}$ & $23,68 \pm 0,81 \mathrm{ab}$ \\
\hline P & $24,15 \pm 0,54 b$ & $25,91 \pm 0,51 \mathrm{~b}$ & $25,31 \pm 0,39 \mathrm{a}$ & $23,53 \pm 0,29 b$ \\
\hline $\mathrm{R}$ & --- & --- & $24,36 \pm 0,52 \mathrm{a}$ & $24,47 \pm 0,64 \mathrm{ab}$ \\
\hline
\end{tabular}

Letras distintas en una misma columna indican diferencias significativas 
Tabla 3. Días entre momento de parto y confirmación de concepción, cantidad de servicios por preñez y días totales en lactancia, según año de parición y genotipo.

\begin{tabular}{lcccc}
\hline & 2007 & 2008 & 2009 \\
& \multicolumn{4}{c}{ Intervalo parto-concepción (días) } \\
\hline F1 & $231,65 \pm 9,2 \mathrm{ab}$ & $138,28 \pm 10,70 \mathrm{a}$ & $118,65 \pm 10,0 \mathrm{~b}$ & $127,0 \pm 14,3 \mathrm{a}$ \\
$\mathrm{G}$ & $177,93 \pm 25,63 \mathrm{bc}$ & $171,64 \pm 21,40 \mathrm{a}$ & $163,62 \pm 9,9 \mathrm{a}$ & $167,6 \pm 7,7 \mathrm{ab}$ \\
$\mathrm{H}$ & $304,36 \pm 64,35 \mathrm{a}$ & $157,75 \pm 34,67 \mathrm{a}$ & $170,00 \pm 30,2 \mathrm{ab}$ & $236,8 \pm 42,0 \mathrm{ab}$ \\
$\mathrm{P}$ & $86,48 \pm 15,05 \mathrm{c}$ & $151,18 \pm 17,07 \mathrm{a}$ & $111,70 \pm 17,4 \mathrm{ab}$ & $253,0 \pm 33,5 \mathrm{a}$ \\
$\mathrm{R}$ & --- & --- & $133,25 \pm 23,1 \mathrm{ab}$ & $170,2 \pm 15,2 \mathrm{ab}$ \\
& \multicolumn{5}{c}{ Cantidad de servicio por preñez } \\
\hline F1 & $3(1-13) \mathrm{a}$ & $1(1-8) \mathrm{a}$ & $1(1-4) \mathrm{a}$ & $2(1-7) \mathrm{a}$ \\
$\mathrm{G}$ & $2(1-12) \mathrm{b}$ & $1(1-6) \mathrm{a}$ & $2(1-13) \mathrm{a}$ & $2(1-9) \mathrm{a}$ \\
$\mathrm{H}$ & $3(1-6) \mathrm{c}$ & $1(1-3) \mathrm{a}$ & $2(1-7) \mathrm{a}$ & $1,5(1-8) \mathrm{a}$ \\
$\mathrm{P}$ & $2(1-4) \mathrm{d}$ & $1(1-6) \mathrm{a}$ & $2(1-5) \mathrm{a}$ & $2(1-8) \mathrm{a}$ \\
$\mathrm{R}$ & --- & --- & $2(1-8) \mathrm{a}$ & $2(1-6) \mathrm{a}$ \\
& \multicolumn{4}{c}{ Días en lactancia } \\
\hline F1 & $449,30 \pm 13,90 \mathrm{a}$ & $331,84 \pm 8,50 \mathrm{a}$ & $320,35 \pm 6,22 \mathrm{~b}$ & $325,6 \pm 8,4 \mathrm{~b}$ \\
$\mathrm{G}$ & $364,43 \pm 17,20 \mathrm{~b}$ & $338,95 \pm 17,01 \mathrm{a}$ & $347,65 \pm 6,17 \mathrm{a}$ & $344,5 \pm 4,6 \mathrm{~b}$ \\
$\mathrm{H}$ & $406,63 \pm 29,39 \mathrm{ab}$ & $332,68 \pm 27,56 \mathrm{a}$ & $352,28 \pm 18,82 \mathrm{ab}$ & $388,1 \pm 25,1 \mathrm{ab}$ \\
$\mathrm{P}$ & $345,09 \pm 16,94 \mathrm{~b}$ & $325,10 \pm 13,57 \mathrm{a}$ & $319,40 \pm 10,87 \mathrm{ab}$ & $400,3 \pm 19,8 \mathrm{a}$ \\
$\mathrm{R}$ & --- & --- & $325,58 \pm 14,38 \mathrm{ab}$ & $348,8 \pm 9,0 \mathrm{ab}$ \\
\hline
\end{tabular}

Letras distintas en una misma columna indican diferencias significativas $(\mathrm{p}<0,05)$.

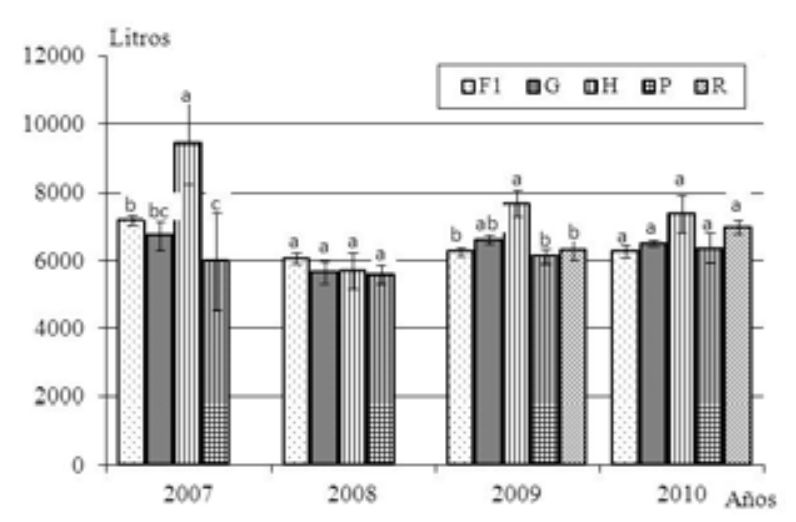

Figura 2. Producción de leche en primera lactancia, según año de parición y genotipo. Letras distintas en un mismo año indican diferencias significativas $(\mathrm{p}<0,05)$.

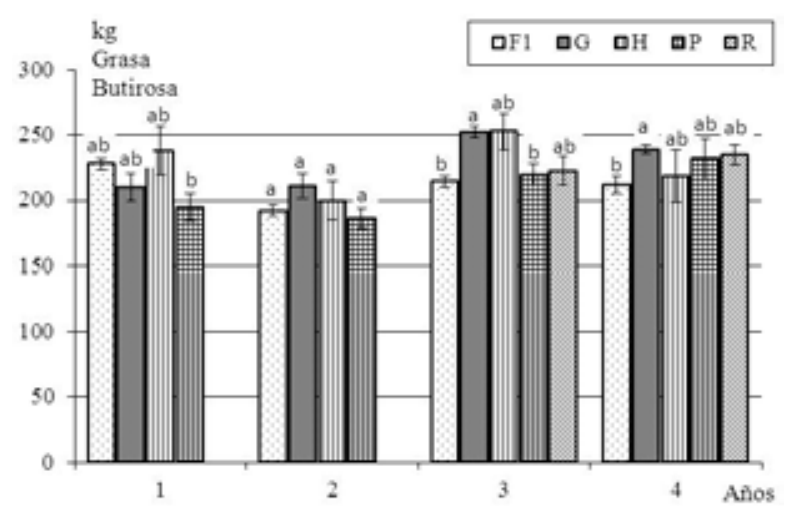

encima de 6.000 litros. Se destaca la H con 9.400 litros el año 2007, cuando las condiciones ambientales y de manejo de la alimentación le permitieron expresar su potencial.

En los demás años este genotipo también presentó los mayores volúmenes de producción individual, siendo solamente superado en 2008 donde, con déficit de precipitaciones y menor oferta de forrajes, se emparejaron todos los genotipos. Se observó que $\mathrm{P}$ formó parte siempre del grupo de menor producción $\mathrm{y}$, por otra parte, se presentó una tendencia a emparejar las producciones en todos los genotipos en el año 2010, con valores entre 6.000 y 7.000 litros.

Producción de grasa butirosa (GB) y proteína total (PT). La producción de GB y PT (Figura 3) se presentó muy variables entre genotipos y años, especialmente GB. Dentro de los genotipos, siempre $\mathrm{H}$ y $G$ se encontraron entre los de mayor producción. Son destacables los valores logrados por F1 el primer año y por R y $\mathrm{P}$ en el año 2010, especialmente en PT. El genotipo $\mathrm{H}$ durante dos años (2007 y 2010) produjo más PT que GB, efecto posiblemente asociado al tipo de alimentación y/o problemas ambientales (estrés calórico en 2010) que habrían repercutido en el tipo de ácidos generados en rumen y/o el metabolismo energético de los animales.

\section{DISCUSIÓN}

El sistema analizado, en general, fue similar al de las principales cuencas lecheras de Argentina, con vacas que pastorean y son suplementadas con forrajes conservados y alimentos concentrados en niveles crecientes, aunque muy vinculados a la relación de precios entre la leche y los granos. Si bien al definir el sistema de producción lechero más adecuado para una dada re-

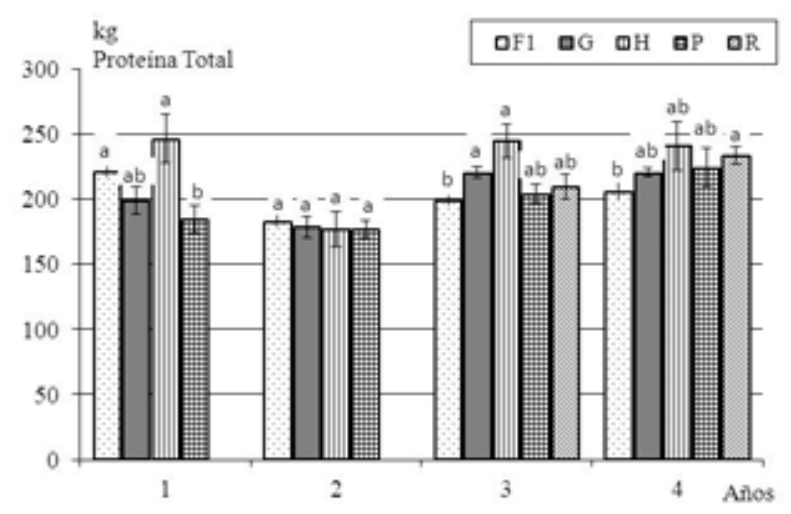

Figura 3. Producción de grasa butirosa y proteína total según año de parición y genotipo. 
gión agroecológica, la elección de la raza o cruza a utilizar debería ser una de las decisiones mejor estudiadas, esto no parece estar resuelto para la situación analizada.

Es conocido que las vacas lecheras poseen requerimientos de energía vinculados especialmente con su mantenimiento y sus niveles de producción. O sea, cuanto más pesada sea la vaca, mayores requerimientos de mantenimiento debe satisfacer $\mathrm{y}$, ante aportes limitados de alimento, podrá derivar menos energía para producir leche e incluso podrían verse afectados sus parámetros reproductivos. Como se observa en los resultados obtenidos en el presente trabajo, el genotipo $\mathrm{H}$ fue el de mayor peso en todos los años, tendiendo a cumplir con la recomendación de llegar al peso al primer parto con alrededor del $90 \%$ del peso adulto. El genotipo de menor peso fue siempre F1, con valores entre 496 y $452 \mathrm{~kg}$ como extremos, aunque en algunos años no se detectaron diferencias con los otros genotipos debido a la variación amplia entre animales.

En relación a la edad al parto, según datos del Control Lechero Oficial Nacional de la Asociación de Criadores de Holando Argentino (ACHA), las vaquillonas llegan al parto a los 32-34 meses de vida $\mathrm{y}$, sobre 106.464 primeras lactancias cerradas en el período 2000-2005 del Control Lechero Oficial, el promedio general de edad al primer parto de vaquillonas fue de 32 meses ${ }^{11}$. Si se considera que la edad óptima al primer parto de vacas lecheras está entre los 22 y 27 meses ${ }^{1}$, los resultados obtenidos en este trabajo señalan que todos los genotipos estudiados se acercan al óptimo teórico en los últimos dos años, con primeros partos entre 23 y 25 meses. Sólo la F1 en el primer año evaluado (2007) mostró un valor superior a los 29 meses, similar a los resultados encontrados en vacas Holstein ${ }^{8}$. El manejo de la recría de vaquillonas en este sistema, para los diferentes genotipos y sus cruzas, podría entonces definirse como adecuado, ya que permite tener una vaca de primer parto a los 24 meses, inseminándola a los 15 meses de edad.

En bovinos lecheros, la búsqueda de mayor eficiencia tanto biológica como económica, requiere de una elevada producción de leche por lactancia y de un buen desempeño reproductivo. En las vacas lecheras los caracteres productivos y reproductivos presentan habitualmente una correlación genética desfavorable, por lo cual un aumento de la producción de leche por selección implica, por lo general, un deterioro de la fertilidad ${ }^{6,10}$. En los sistemas productivos en pastoreo esta incompatibilidad se torna extrema ${ }^{5,8}$. Trabajos realizados mostraron que la cruza F1 (HxJ) pareciera tener un mejor comportamiento reproductivo en los sistemas a pastoreo ${ }^{2,5}$, hecho que podría atribuirse a la combinación de sus menores requerimientos de mantenimiento y al efecto heterótico puesto de manifiesto en las hembras cruzas.

En los resultados encontrados en el presente trabajo, $\mathrm{H}$ siempre mostró una baja eficiencia reproductiva confirmando en tal sentido que, a mayor producción, se incrementa el ipc. Este deterioro reproductivo también se evidencia en las cruzas, donde la búsqueda de una mayor producción individual en las vacas podría estar anulando o disminuyendo su posible ventaja en tal aspecto frente al genotipo Holstein, tal como se mencionó anteriormente, lo cual puede apreciarse claramente en los resultados obtenidos en el año 2008. La cantidad de días en lactancia tiene una relación directa con la producción individual, evidenciando que las vacas se mantienen más días en lactancia debido a que poseen un mayor intervalo parto concepción. De la misma manera se comportaron los distintos genotipos y cruzas para la producción de GB y PT en los años estudiados, ambas fueron muy variables y tuvieron una alta relación con la alimentación recibida y el ambiente climático.

Los resultados obtenidos coinciden con trabajos ${ }^{4,5}$ que demuestran que el comportamiento productivo y reproductivo de los genotipos y sus cruzas parecen estar muy influenciados por el ambiente nutricional, ya que en condiciones de mayor disponibilidad de calidad y cantidad de alimentos concentrados, el genotipo Holstein supera en producción de leche a las cruzas, pero al mismo tiempo es el genotipo más afectado cuando existen restricciones alimenticias, situación similar a lo acontecido en el actual estudio.

Existieron diferentes comportamientos de las variables analizadas dentro de cada genotipo, con diferentes respuestas para cada uno de ellos según el año analizado, lo cual no permitió explicar adecuadamente la posible adaptación o no de los animales al ambiente y manejo del sistema. Podría afirmarse que las cruzas F1 y G fueron las más estables en producción y las que presentaron las mejores respuestas reproductivas para estas condiciones, pero sería importante repetir el análisis utilizando indicadores agregados que permitan confirmar esta presunción e identificar el genotipo mejor adaptado.

Agradecimientos. A los ingenieros Santiago Brandi y Fabián Alvarez Leroy, del establecimiento "El Caraguatá" S.A., por su colaboración en la recopilación de información, discusión técnica de los avances y apoyo financiero para la realización de este trabajo.

\section{REFERENCIAS}

1. Bouissou RG. 1997. Edad al primer parto. Rev Marca Líquida (Córdoba, Argentina) 64: 41-44.

2. Dutour EJ, Laborde D, Meikle A, Chilibroste P. 2010. Comportamiento reproductivo de vacas primíparas de diferentes grupos raciales en un sistema pastoril de producción de leche. Rev Arg Prod Anim 30: 85-108.

3. Faust M.A. 2005. Análisis de cruza entre razas lechera (ABS México). On line: http://www.engormix.com/MAganaderia-leche/genetica/articulos/analisis-cruza-entrevacas-t414/103-p0.htm.

4. Krall E. 2003. Análisis de registros de predios comerciales. Ganado Holando, Jersey y sus cruzas para producción de leche. Rev Plan Agropec (Montevideo, Uruguay) 107: 31-35. 
5. Krall E, Mancuso W, Casado E. 2005. Comparación de dos grupos genéticos en un predio lechero pastoril de la cuenca lechera este de Entre Ríos. Anales $33^{\circ}$ Jornadas Buiatría (Paysandú, Uruguay), p. 179-181.

6. Löf E, Gustafsson H, Emanuelson U. (2007). Associations between herd characteristics and reproductive efficiency in dairy herds. J Dairy Sci 90: 4897-4907.

7. Madalena FE. 2001. Consideraciones sobre modelos para predicción del desempeño de cruzamientos en bovinos. Arch Latinoam Prod Anim 9: 108-117.

8. Marini PR. 2004. Indicadores productivos y reproductivos de vacas de diferentes edades al primer parto en sistemas a pastoreo. Arch Zoot (España) 53: 202-208.
9. Molinuevo HA. 2005. Genética bovina y producción en pastoreo. Ed. INTA (Buenos Aires), 348 p.

10. Rodríguez-Martinez H. et al. 2008. La eficiencia reproductiva en vacas lecheras de alta producción. IVIS Reviews in Vet Med (Ithaca USA), http://minnie.uab.es/ veteri/ 00011/Eficiencia\%20reproductiva\%20vacas.pdf.

11. Snyder M. 2006. La recría de vaquillonas en el negocio del tambo. Rev Producir XXI (Buenos Aires) 14: 43-49. 